\title{
Ceramic matrices applied to aerostatic porous journal bearings: material characterization and bearing modeling
}

\section{(Matrizes cerâmicas com aplicação em mancais aerostáticos cerâmicos porosos: caracterização do material e modelagem do mancal)}

\author{
Z. C. Silveira, R. Nicoletti, C.A. Fortulan, B. M. Purquerio \\ Departamento de Engenharia Mecânica, Escola de Engenharia de S. Carlos, Universidade de S. Paulo, Av. \\ Trabalhador S.-Carlense 400, S. Carlos, SP 13566-590 \\ silveira@sc.usp.br,rnicolet@sc.usp.br,cfortula@sc.usp.br,purqerio@sc.usp.br
}

\begin{abstract}
This paper presents the development of an advanced ceramic material for manufacturing aerostatic porous bearing. The results show that there is homogeneous distribution of the pores in the alumina matrix by using different concentrations of the added component (sucrose). The average pore diameter remained around $0.14 \mu \mathrm{m}$ and respective porosity around $28 \%$, with small standard deviation. The mathematical model of the aerostatic porous bearing is presented, and numerical results indicate that the parameter related to porous medium $(\Gamma)$ strongly affects the resultant bearing load capacity and stiffness. Considering the experimental and numerical results, the porous matrix obtained with $40 \%$ of sucrose concentration is more suitable for the aerostatic porous bearing application in study.
\end{abstract}

Keywords: porous ceramic materials, aerostatic bearings, permeability identification, bearing modeling.

\section{Resumo}

Este trabalho apresenta o desenvolvimento de materiais cerâmicos porosos, obtidos a partir de cerâmicas estruturais (alumina), para a fabricação de mancais aerostáticos. Os resultados iniciais indicaram que, houve homogeneidade na distribuição dos poros na matriz de alumina, obtida com diferentes concentrações de agente poroso (sacarose). O valor médio dos poros foi de 0,14 $\mu m$, com porosidade em torno de $28 \%$, apresentando um pequeno desvio-padrão. O modelo matemático do mancal aerostático poroso é apresentado e os resultados numéricos indicaram que o parâmetro adimensional ( $\Gamma)$ relacionado com o meio poroso afeta significativamente a capacidade de carga e rigidez do mancal. Considerando os resultados experimentais e numéricos, a matriz porosa obtida com $40 \%$ de concentração induzida de sacarose é a mais adequada, para a fabricação de mancais aerostáticos cerâmicos porosos.

Palavras-chave: cerâmica porosa, mancais aerostáticos, identificação da permeabilidade, modelagem de mancais.

\section{INTRODUCTION}

The increasing industrial demand on microelectronic and micro electromechanic components, mainly in the nanotechnology field, has levered up the design and manufacturing of ultra precision machines. The required tolerances during manufacturing process, which are usually in the order of $1 \mu \mathrm{m}$, with a resolution of $1 \mathrm{~nm}$, are a consequence of this new precision needs in micro component industry [1].

The performance of an ultra precision machine directly depends on the static and dynamic behavior of its components. Some fundamental characteristics are the rotational and linear precision, stiffness, movement repeatability and load capacity. The rotor-bearing pair in such machines plays an important role in setting the fundamental characteristics just mentioned. Considering these facts, aerostatic bearings are more suitable for spindle and linear guides applications due to their inherent characteristics. The use of air as the lubrication fluid in the bearings brings several operational advantages, for instance the low wear and noise between moving parts, low contamination, movement precision and repeatability, high load capacity, feasibility of achieving high rotating speeds, and long component life.

The idea of using a porous matrix as the air injection mechanism of the aerostatic bearing has additional advantages, such as the cost reduction in manufacturing, easy of assemblage, shorter periodic maintenance needs, and better results of the design and operation, considering parameters as load capacity and stiffness. The adoption of ceramic materials to be used in porous bearing allows the machining through grinding without the deformation and blocking of the surface micro porosity, which is a clear advantage relatively to metallic porous surfaces. Literature provides many works related to the identification and characterization of porous aerostatic bearings. Majumdar 
[2] proposed a design procedure to externally pressurized gas-lubricated metallic porous journal bearing considering static loading. The static behavior is related to the effect of the feeding parameter. These studies verified that the load capacity reaches a maximum value and decreases with further increase in feeding parameter $(\Gamma)$. Yoshimoto and Kohno [3] studied aerostatic circular porous thrust bearings built with graphite porous material. Two feeding systems were used: the annular grove air supply method and the orifice air supply method. In this study, it was observed that the shape of supply area has little influence on the static stiffness when the outer diameter of the supply area remains the same. The load capacity and damping coefficient of aerostatic thrust bearing with a restricted layer depends on the dimensionless parameter that is related to the permeability coefficient in radial direction and thickness of porous material. Fourka and Bonis [4] investigated externally pressurized gas thrust bearings with different orifice and porous feeding systems. The authors compared the optimum characteristics regarding load capacity, stiffness and flow rate of an air thrust bearing using different kinds of multiple inlets designed with orifices or porous compensation. The study indicated that a better performance may be achieved for each feeding system, which depends on an optimum number of inlets, orifice position or permeability coefficient of the porous material. Balestrero [1] compared the bearing load capacity and stiffness of two aerostatic bearings using pocket orifice restrictors and porous inserts. The results indicated a best performance for the bearing with porous inserts regarding both load capacity and stiffness. The achieved bearing stiffness was $120 \mathrm{~N} / \mu \mathrm{m}$ for the bearing with pocket orifice restrictors and $300 \mathrm{~N} / \mu \mathrm{m}$ for the bearing with porous inserts. Plante, Vogan, El-Aguizy, and Slocum [5] presented a design model for a circular porous air bearing using onedimensional generalized flow theory focusing on the essential physical phenomena governing the airflow. The authors compared the results of the one-dimensional model to the results generated by the three-dimensional model, regarding force versus bearing gap and corresponding flow rates. The conclusion was that the one-dimensional model had a good agreement with experimental data, because the physics of the flow in the porous media was properly considered. Majumdar [6] presented a theoretical procedure to derive the steady-state performance characteristics of stationary and rotating journals, by considering a three-dimensional flow in the porous material of a bearing. In this way, he demonstrated that the dynamic characteristics of the gas film is fundamental to response of gas bearing supported systems and that the important parameters are the film stiffness, the damping, and the stability range. Majumdar [7], on the other hand, presented a literature review on theoretical models to obtain stiffness and damping values of external pressurized, rectangular and porous thrust bearings.

The geometry and intercommunication of pores in advanced ceramics has a direct correspondence to the permeability property of the material, which is represented by the permeability viscous coefficient $\left(\mathrm{k}_{1}\right)$ considering laminar flow in the fluid. Kwan and Corbett $[8,9]$, Fourka and Bonis [4] and Yoshimoto and Kohno [3] cite values of permeability viscous coefficients between $10^{-16}$ and $10^{-12} \mathrm{~m}^{2}$ in experimental and numerical studies. The work of Kwan and Corbett [8] involves the determination of permeability inertial coefficients and the effect of the slip velocities in the porous media of air bearings, considering turbulent flow as well as surface roughness. This value estimation is essential to design porous ceramic bearings that present acceptable operation range of high stiffness and damping.

In this work, one proposes the manufacturing process of the porous ceramic material that will be used in aerostatic porous bearings of ultra precision machines. The material characterization, regarding size and pore distribution, and the resultant permeability, is experimentally presented for different concentrations of pore-forming agents. The effect of such permeability in bearing dynamic characteristics (load capacity and stiffness) is numerically investigated through the mathematical model of the aerostatic bearing. Finally, based on the experimental and numerical results, the best concentration of pore-forming agents is indicated for the application in focus (ceramic porous aerostatic bearing for ultra precision machines, spindles and guide ways).

\section{POROUS CERAMIC MATRIX CHARACTERIZATION}

A set of samples of porous ceramic structures was obtained using different concentrations of pore-forming agent and different times of milling. The determination of the pore size and distribution is analyzed by scanning electron Microscopy (SEM) and mercury porosimetry. The chosen method to obtain the pores considers the addition of an element that must be dispersive, degradable and volatile with the increase of the temperature [10].

In this work, the sucrose was chosen as the addition element because it does not react with the alumina matrix during the burning process, presenting low cost and easy acquisition. The selected forming processes to obtain the bearing samples are the uniaxial and the cold isostatic pressing. The bearing samples were compacted and sinterized at a temperature of $1600{ }^{\circ} \mathrm{C}$. The materials used to obtain the porous ceramic matrices were: alumina A1000 SG (Almatis) with diameter of $0.5 \mu \mathrm{m}$; sucrose (Labynth); polivinil-butirol (PVB) for superficial adhesion of Butvar B-98 resin and isopropyl alcohol (Labynth).

The mixture and homogenization of the ceramic material used for the preparation of the ceramic slurry were made in a ball mill using a jar with $400 \mathrm{~mL}$ of useful volume capacity. The ceramic slurry was composed by $30 \mathrm{vol} . \%$ by alumina plus sucrose, and 70\% with isopropyl alcohol and PVB. The size of sucrose particles to obtain the induced porosity was between 177 and $300 \mu \mathrm{m}$ or ASTM 80 and 48. The volume concentrations of the ceramic material were $35,40,50$, and $55 \%$. The milling time of sucrose suspension on isopropyl alcohol varied from 3 to $6 \mathrm{~h}$. The final milling time with the addition of alumina and PVB was $2 \mathrm{~h}$. After the mixture and milling of the elements, the solvent was evaporated using an 

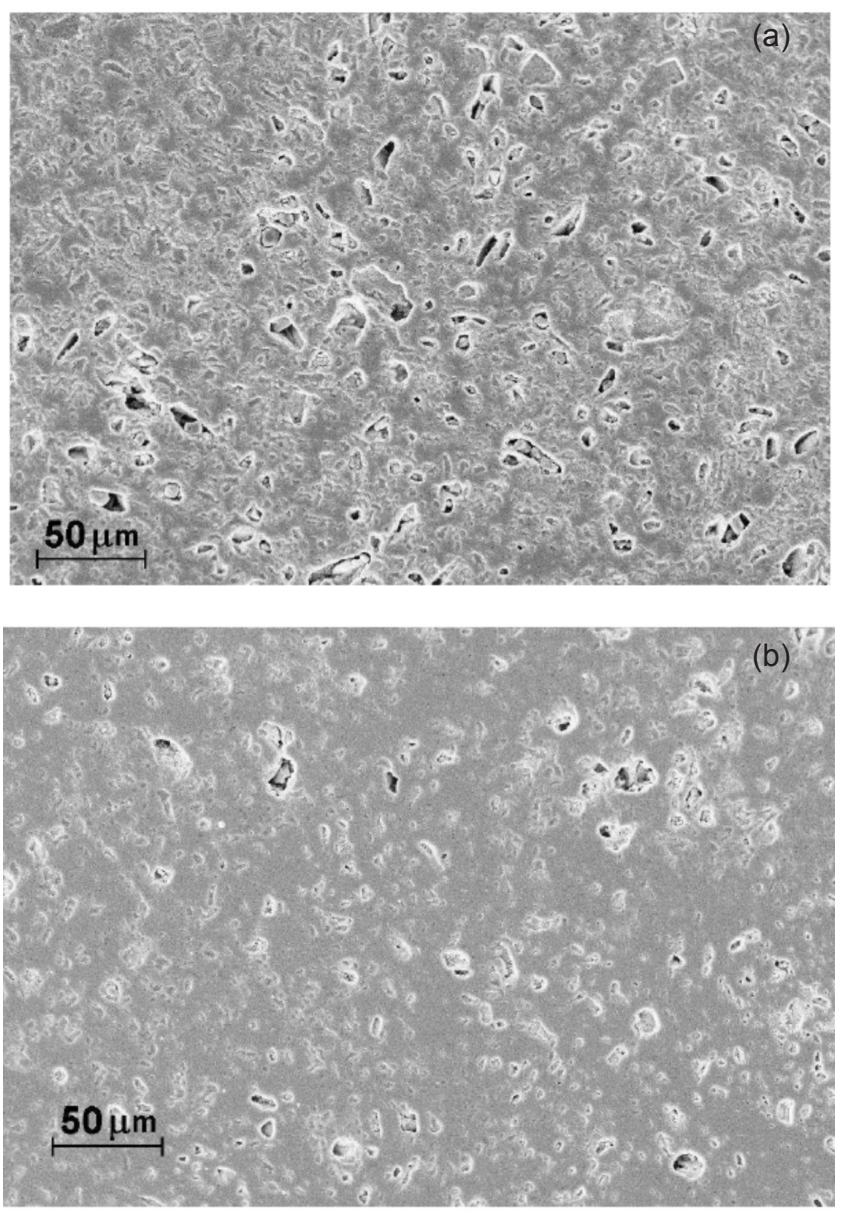

Figure 1: Sections of material samples (SEM images). a) 40\% sucrose (1000x); b) 55\% sucrose (1000 x).

[Figura 1: Seções das amostras do material (Imagens do MEV). a) 40\% sacarose (1000x); b) 55\% sacarose (1000x).]

Table I - Material porosity (experimental results). [Tabela I-Porosidade domaterial (resultados experimentais.]

\begin{tabular}{ccc}
\hline $\begin{array}{c}\text { Sucrose concentration } \\
(\%)\end{array}$ & $\begin{array}{c}\text { Average pore } \\
\text { diameter } \\
(\mu \mathrm{m})\end{array}$ & $\begin{array}{c}\text { Average } \\
\text { porosity } \\
(\%)\end{array}$ \\
\hline 35 & 0.1050 & 23.43 \\
40 (uniaxial press.) & 0.1738 & 34.00 \\
40 (isostatic press.) & 0.1322 & 32.00 \\
50 & 0.4622 & 31.07 \\
55 & 0.1651 & 26.36 \\
\hline
\end{tabular}

air heat blower until a ceramic powder with grains around $300 \mu \mathrm{m}$ is obtained. After that, the ceramic powder is dried in a box furnace at $80{ }^{\circ} \mathrm{C}$ during $30 \mathrm{~min}$.

The circular material samples were axially pressed to final dimensions of the $32 \mathrm{~mm}$ in diameter and $5 \mathrm{~mm}$ thickness. The ceramic powder was deposited in a mechanical mould and uniaxially pressed under $80 \mathrm{MPa}$. The cold isostatic pressing was applied only in an additional sample with concentration of sucrose of $40 \%$. This sample was encapsulated under vacuum and involved in a rubber mould, and isostatically pressed under $100 \mathrm{MPa}$. All samples were dried in a box furnace with gradual increase of temperature to evaporated the sucrose and sintering. The sintering was done following the temperature ramp: $1{ }^{\circ} \mathrm{C} / \mathrm{min}$ from room temperature to $370{ }^{\circ} \mathrm{C}, 5{ }^{\circ} \mathrm{C} / \mathrm{min}$ from $370{ }^{\circ} \mathrm{C}$ to $600{ }^{\circ} \mathrm{C}$, $10{ }^{\circ} \mathrm{C} / \mathrm{min}$ from $600{ }^{\circ} \mathrm{C}$ to $1600{ }^{\circ} \mathrm{C}$. The samples remained at $1600{ }^{\circ} \mathrm{C}$ for $120 \mathrm{~min}$ and $28{ }^{\circ} \mathrm{C} / \mathrm{min}$ from $1600{ }^{\circ} \mathrm{C}$ down to room temperature [11].

Figs. 1a and 1b show images of the sample sections with different concentrations of the sucrose in the total volume. The obtained pores presented a uniform distribution in the samples with averaged values of pore diameter between 0.04 and $30 \mu \mathrm{m}$. Despite the high amount of sucrose added to ceramic material, the final porosity does not correspond to the used initial values. For example, using 55\% of sucrose, the final achieved porosity was around $26 \%$. The porosity values for different concentrations of sucrose are presented in Table I. According to the results, sintering at $1600{ }^{\circ} \mathrm{C}$ was quite enough to eliminate a significant part of the inherent pores.

The analysis using the porosimeter allows estimating the pore size and distribution in the alumina matrix as a function of sucrose concentration. Each sample had different times of milling along of the manufacturing process. The time control was fundamental because the ceramic presents a fragile structure with low toughness. Hence, a wrong estimation of the control time can present sparse distribution of particle size and shape. The right choice of milling time helps getting an average pore diameter values with narrow standard deviation, leading to a homogeneous condition. This condition was reached with milling time from 3 to 4 $\mathrm{h}$ for the sucrose mixture with isopropyl alcohol, and $2 \mathrm{~h}$ for the mixture of ceramic slurry. The porosity control was made with the control of induced porosity related to the sucrose concentration and milling time. Figs. 2 and 3 present the results obtained for the sucrose concentrations of $40 \%$ and $55 \%$, respectively.

The permeability is a fundamental physical property of the development and design of aerostatic porous bearings, because it is related to the air flow that is injected into the bearing clearance. The permeability is the quantitative parameter that represents the capacity of a fluid to transpose the porous medium. Therefore, it is an important characteristic for the design and manufacturing of lubricated air bearing with porous surfaces. The values of the viscous and inertial permeability coefficients are directly dependent on the material porous structure, without a direct relationship with the air flow rate or Reynolds number [12]. To obtain higher stiffness and a stable operational range in porous bearings, the viscous permeability coefficient must be less than $10^{-12} \mathrm{~m}^{2}$ [4] and the inertia permeability coefficient around $10^{-9} \mathrm{~m}[4,8,13]$.

Darcy (1856) [in 12] demonstrated through an empirical equation that the energy modification of the fluid is caused by its flow through a porous medium. He observed that the pressure drop is linear to the flow, and established a proportionality constant $\mathrm{k}_{1}$ known as Darcian permeability 

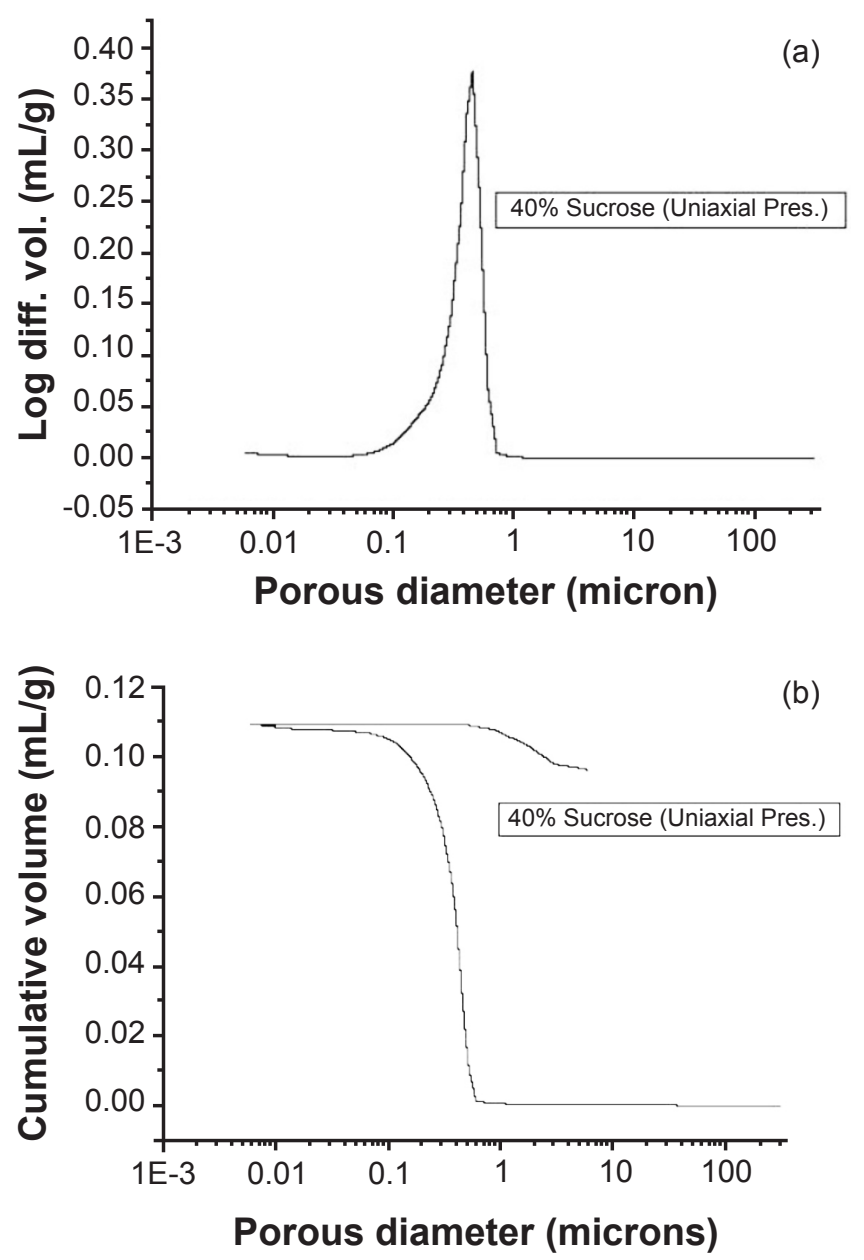

Figure 2: Mercury porosimetry results for the sucrose concentration of $40 \%$. a) Cumulative curve; b) Normal curve.

[Figura 2: Resultados da porosímetria de mercúrio para a concentração de $40 \%$ de sacarose. a) curva cumulativa; b) curva normal.]

or viscous permeability coefficient. The Darcy's equation for incompressible fluids is given by the equation:

$$
-\frac{\mathrm{dp}}{\mathrm{ds}}=\frac{\eta}{\mathrm{k}_{1}} v
$$

In Eq. A $d p / d s$ represents the pressure drop $\Delta p=p-P_{S}$ along of the thickness of the porous sample, $\eta$ is the air dynamic viscosity, $\mathrm{k}_{1}$ is the viscous permeability coefficient, and $v$ represents the superficial velocity of the fluid through the porous surface. The viscous permeability coefficient $\left(\mathrm{k}_{1}\right)$ of the porous medium is unique for any fluid, because it is the result of the mechanical interaction between the porous medium and the fluid generating an energy transformation of the system. Forchheimer (1901) [in 12] proposed the incorporation of inertia effects in the Darcy's equation, considering the quadratic relationship due the higher velocities and turbulent regimes with an increase of Reynolds number. The following equation represents this modification:

$$
-\frac{\mathrm{dp}}{\mathrm{ds}}=\frac{\eta}{\mathrm{k}_{1}} v+\frac{\rho}{\mathrm{k}_{2}} v^{2}
$$
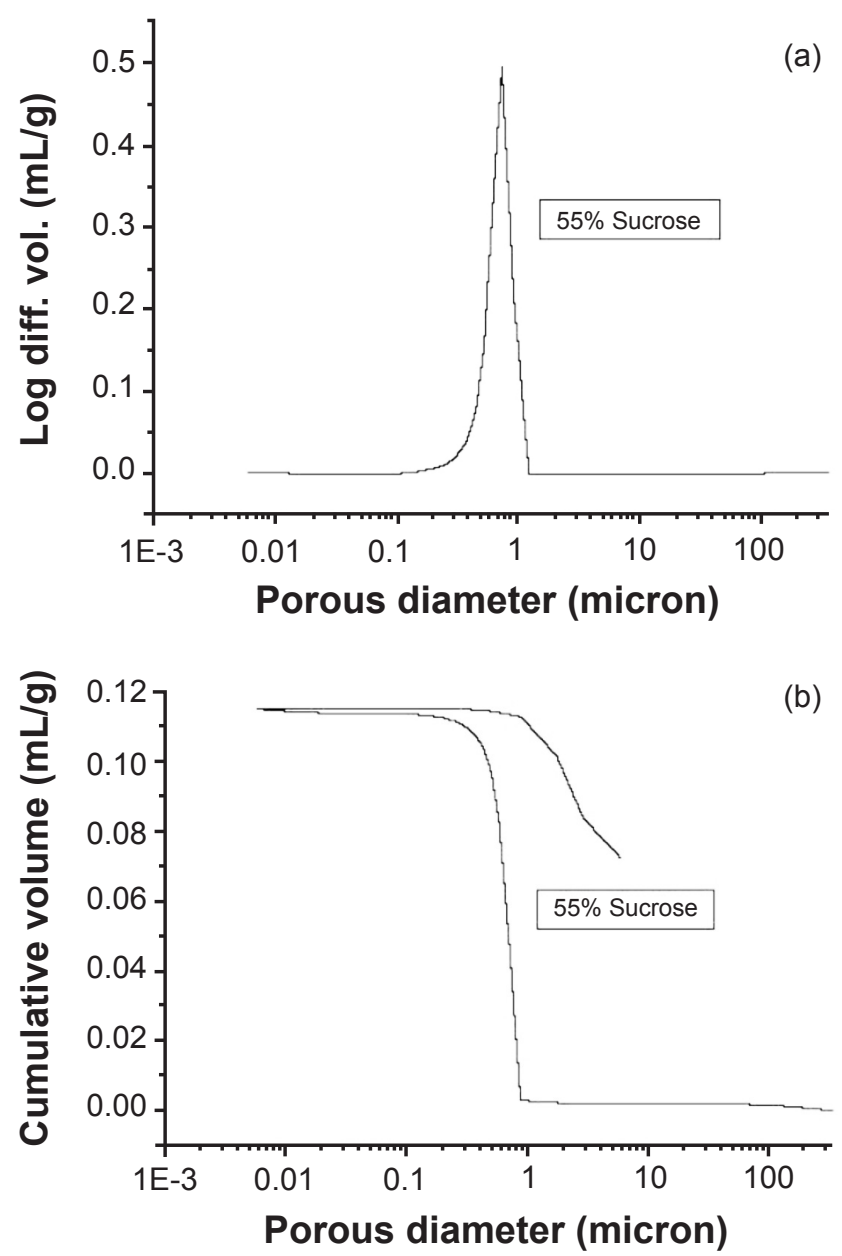

Figure 3: Mercury porosimetry results for the sucrose concentration of $55 \%$. a) Cumulative curve; b) normal curve.

[Figura 3: Resultados da porosímetria de mercúrio para a concentração de 55\% de sacarose. a) curva cumulativa; b) curva normal.]

In Eq. $\mathrm{B} \rho$ represents the density of fluid, $\mathrm{k}_{2}$ is the inertia permeability coefficient, and $v$ represents the superficial velocity of fluid obtained by the quotient between the mass flow and the section of the orthogonal area to the flow direction. The first term in the right side of the equation represents the viscous effects due to the friction of the interaction fluid-surface, and the second term represents the inertial effects [14].

The permeability measurement of the material samples were made using the experimental set-up (permeameter) based on Darcy's principle that consider the difference of pressure due the fluid passage in a porous medium, based on the ISO 4022:1987 [15]. The equipment has a cylindrical chamber manufactured with a polyvinyl chloride tube with $1 \mathrm{~m}$ length. The air flow in the tube is perpendicular to the sample that is positioned inside in a holder. The holder is located in the middle distance between the pressure gauges that are fixed along the chamber, allowing measurements independently of the sample thickness. The long feeding tube connected to the sample holder leads the fluid directly to the sample in order to reduce possible flow turbulences 
[12]. Fig. 4 shows the general view of the set-up indicating the position of flow meters and the electric pressure gauges. Two air filters are located in the compressed air line, one for pre-filtering (40 $\mu \mathrm{m}$ grid) and another for coalescence with $0.01 \mu \mathrm{m}$ grid. During the experimental tests, the room remained in ambient temperature, around $21{ }^{\circ} \mathrm{C}$, the air density was assumed to be $1.079 \mathrm{~kg} / \mathrm{m}^{3}$ and air dynamic viscosity to be $1.83 \times 10^{-5}$ Pa.s. Measurements were made in duplicates for each experimental test to get an average value of the difference of pressure, and to guarantee the data repeatability.

The viscous and inertia permeability coefficients were obtained and fitted to equations A and B. Fig. 5 presents the fitted curves, which show that the sucrose concentrations of $55 \%$ and $40 \%$ present a linear tendency, which suggest a laminar flow of the air through the samples. In the sample with concentration of 55\% there was a small variation in the pressure drop. This variation can be caused by the presence of the material inherent porous or small induced porous that restrict the flow. The sample with concentration of $40 \%$ (formed by uniaxial pressing) presented a higher mass flow than that with concentration of $55 \%$, because the pressure drop is higher. The samples with sucrose concentrations of $35 \%, 50 \%$ and $40 \%$ (formed by isostatic cold pressing) presented some difficulties for air flow in the porous medium, evidenced by the non-linear curves, probably

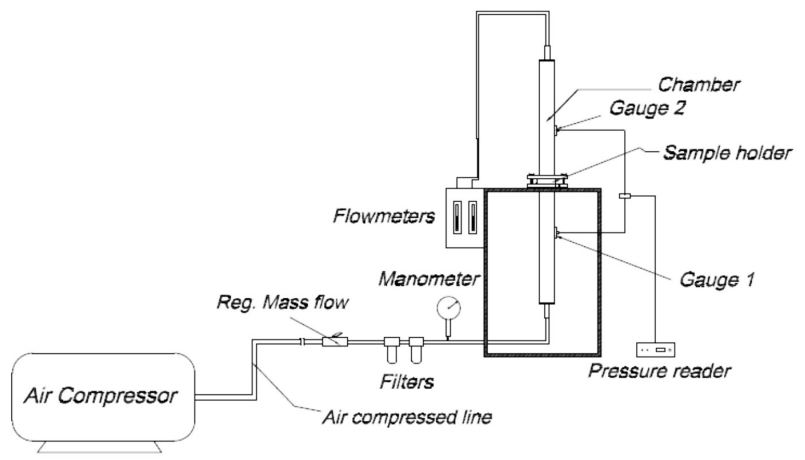

Figure 4: Experimental set-up for measuring material permeability (permeameter).

[Figura 4: Montagem experimental para a medida de permeabilidade do material (permeâmetro).]

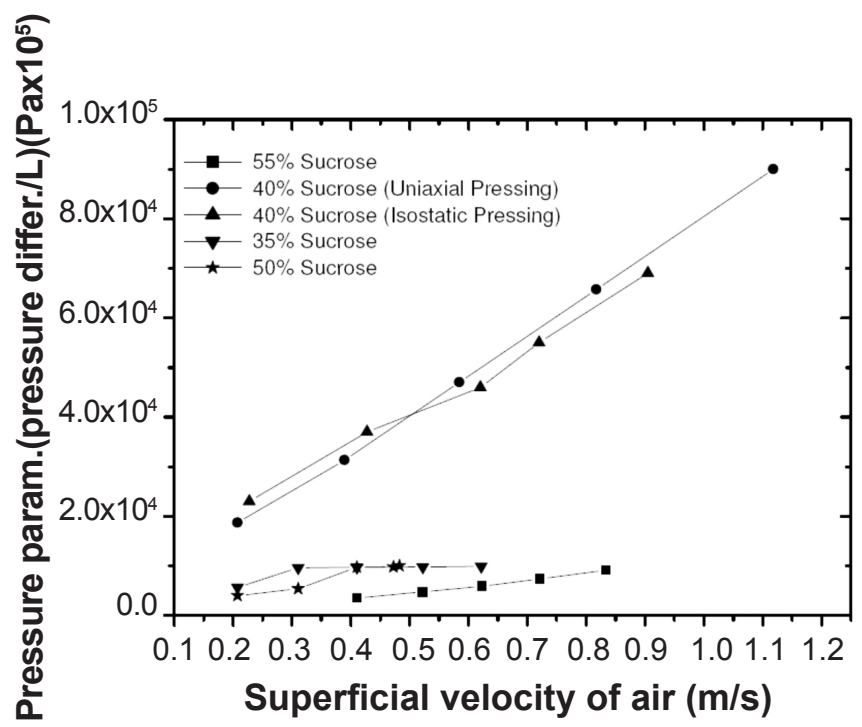

Figure 5: Experimental results of pressure drop versus air flow velocity through the porous matrix.

[Figura 5: Resultados experimentais da diferença de pressão $x$ velocidade de escoamento através da matriz porosa.]

caused by the presence of closed pores in the material and/ or due to irregular geometry of the sucrose particles that can also restrict the fluid flow. The obtained viscous permeability coefficients achieved the minimum values required for the use in aerostatic bearings $[4,8,16]$, with the exception of the results presented by the sucrose concentration of $35 \%$. The permeability results are presented in the Table II. The obtained inertia permeability coefficients are above the values referenced in the literature $\left(10^{-9} \mathrm{~m}\right)$.

There are two questions attributed to this difference, one is related to the pore geometry and the other to the presence of inherent closed pores of the material. In the first case, $\mathrm{k}_{1}$ and $\mathrm{k}_{2}$ can be improved by modifying the geometry of the pore-forming agent. The choice of an element with elongated shape and more defined contour certainly would modify and improve the percolation through the pores in the material. This modification would significantly increase the specific area, resulting in higher permeability values with more optimized geometrical configurations of porosity. The pressure range for the aerostatic bearings is between 3.0 and

Table II - Material permeability (experimental results).

[Tabela II - Permeabilidade do material (resultados experimentais).]

\begin{tabular}{cccc}
\hline $\begin{array}{c}\text { Sucrose concentration } \\
(\%)\end{array}$ & $\begin{array}{c}\text { Viscous permeability } \\
\text { coefficient } \mathrm{k}_{1} \\
\left(\mathrm{~m}^{2}\right)\end{array}$ & $\begin{array}{c}\text { Inertia permeability } \\
\text { coefficient } \mathrm{k}_{2} \\
(\mathrm{~m})\end{array}$ & $\begin{array}{c}\text { Specific area } \\
\left(\mathrm{m}^{2} / \mathrm{g}\right)\end{array}$ \\
\hline 35 & $1.09 \times 10^{-11}$ & $2.1 \times 10^{-5}$ & 1.920 \\
40 (uniaxial press.) & $1.14 \times 10^{-12}$ & $1.9 \times 10^{-4}$ & 2.091 \\
40 (isostatic press.) & $1.36 \times 10^{-12}$ & $6.3 \times 10^{-5}$ & 1.923 \\
50 & $3.80 \times 10^{-12}$ & $2.2 \times 10^{-4}$ & 1.149 \\
55 & $6.81 \times 10^{-12}$ & $1.2 \times 10^{-4}$ & 2.304 \\
\hline
\end{tabular}


5.0x $10^{5} \mathrm{~Pa}$, and the improvement of the superficial area of the bearing allow the adoption of such operational pressures. In the second case, the solution is limited to the type of compacting process.

\section{Mathematical modeling of porous journal bearing}

The aerostatic ceramic porous bearing in study is a journal bearing whose casing is made of porous ceramic material (Fig. 6). Pressurized air at pressure $P_{S}$ is injected into the bearing gap (h) through the porous surface of the ceramic matrix that composes the bearing casing, thus forming an aerostatic pressure distribution in the bearing gap.

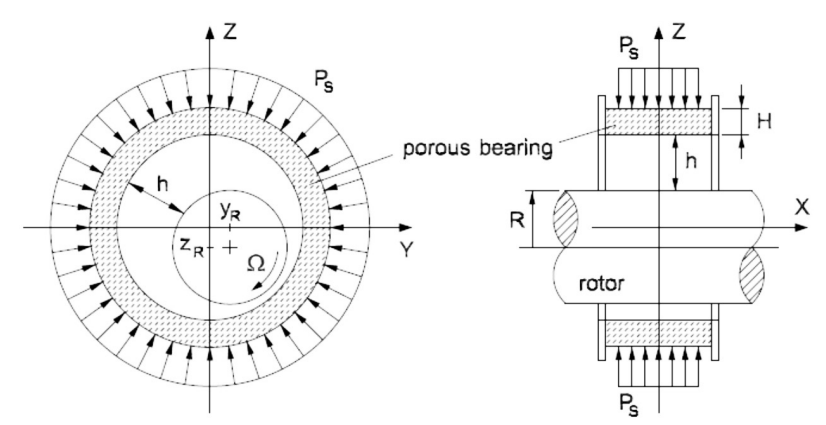

Figure 6: Schematic view of the aerostatic ceramic pouros bearing. [Figura 6: Esboço do mancal aroestático ceramico poroso]

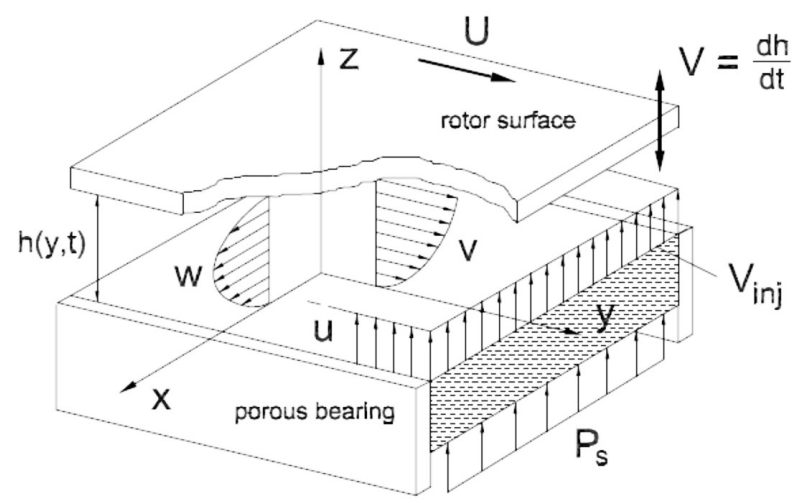

Figure 7: Fluid flow kinematics, velocity profiles and nonslip boundary conditions in the bearing gap.

[Figura 7: Cinemática do escoamento do fluido $x$ condições de contorno sem escorregamento na folga do mancal.]

In order to calculate the aerostatic pressure distribution in the bearing gap, one assumes that the fluid is isoviscous, Newtonian, compressible, and operating in the laminar regime. Thus, one can simplify the Navier-Stokes equations, and rewrite them in the reference frame fixed in the bearing, supposing that the considered bearing area for analysis is part of a shallow and long channel (Fig. 7). The fluid flow nonslip boundary conditions in the bearing gap are also shown in Fig. 7.
Integrating the Navier-Stokes equations subjected to the nonslip boundary conditions (Fig. 7), one gets the expressions for the fluid velocity profiles in the bearing gap. Inserting the expressions for the fluid velocity profiles into the continuity equation, and integrating it between the limits $[0, \mathrm{~h}]$, one obtains the modified Reynolds equation as a function of the injection velocity $\mathrm{V}_{\text {inj }}$, as follows:

$\frac{\partial}{\partial x}\left(\frac{h^{3} p}{\eta} \frac{\partial p}{\partial x}\right)+\frac{\partial}{\partial y}\left(\frac{h^{3}}{\eta} \frac{\partial p}{\partial y}\right)=6 U \frac{\partial(p h)}{\partial y}+12 \frac{\partial(p h)}{\partial t}-12 p V_{\text {inj }}$

Where one considers a perfect gas fluid (air), under isothermal condition $(\rho=p / \mathcal{R} T$, $)$ which is usually acceptable under pressures below $10 \times 10^{5} \mathrm{~Pa}$ [17].

Considering the assumption that the air flow through a porous medium is linearly proportional to the pressure difference, one has the linearized Darcy equation (Eq. A). This equation is commonly used to express the relationship between the pressure drop $(\Delta \mathrm{p})$ and the flow velocity $(\mathrm{v})$ by the coefficient $\mathrm{k}_{1}$. However, the flow velocity depends on the cross sectional area of the sample. This means that, for a different cross sectional area, the same material sample will present a different flow velocity, therefore resulting in a different value of $\mathrm{k}_{1}$. In the case of a porous radial bearing, where the cross section area varies (Fig. 8), the flow average velocity in a section of the bearing is given by:

$$
v(\mathrm{r})=\frac{\mathrm{Q}_{\mathrm{m}}}{\delta \theta \cdot \delta \mathrm{L} \cdot \rho} \frac{1}{\mathrm{r}}
$$

Where $\mathrm{Q}_{\mathrm{m}}$ is the mass flow rate through the porous matrix.

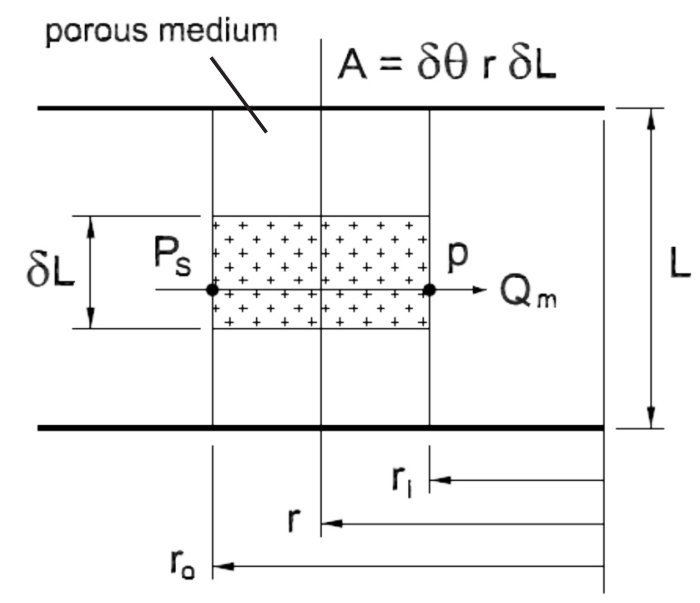

Figure 8: Schematic view of a section of the porous bearing (radial bearing).

[Figura 8: Esboço de uma seção do mancal poroso (mancal radial).]

Inserting Eq. D into the Darcy equation (Eq. A):

$$
-\frac{\mathrm{dp}}{\mathrm{dr}}=\frac{\mathrm{Q}_{\mathrm{m}}}{\mathrm{k}_{1} \delta \theta \cdot \delta \mathrm{L} \cdot \rho} \frac{1}{\mathrm{r}}
$$

Integrating Eq. $\mathrm{E}$ from $r_{\mathrm{i}}$ (bearing inner radius) to $r_{o}$ 
(bearing outer radius), and rearranging it:

$$
\mathrm{Q}_{\mathrm{m}}=\frac{\mathrm{k}_{1} \delta \theta \cdot \delta \mathrm{L} \cdot \rho\left(\mathrm{P}_{\mathrm{s}}-\mathrm{p}\right)}{\eta \cdot \ln \left(\mathrm{r}_{\mathrm{o}} / \mathrm{r}_{\mathrm{i}}\right)}
$$

Considering that the injection velocity of air in the bearing gap for the bearing section is the air velocity (Eq. D) in the sliding surface of the bearing $\left(r=r_{i}\right)$ :

$$
\mathrm{V}_{\mathrm{inj}}=v\left(\mathrm{r}_{\mathrm{i}}\right)=\frac{\mathrm{Q}_{\mathrm{m}}}{\delta \theta \cdot \delta \mathrm{L} \cdot \rho \cdot \mathrm{r}_{\mathrm{i}}}=\frac{\mathrm{k}_{1}\left(\mathrm{P}_{\mathrm{s}}-\mathrm{p}\right)}{\eta \cdot \mathrm{r}_{\mathrm{i}} \ln \left(\mathrm{r}_{\mathrm{o}} / \mathrm{r}_{\mathrm{i}}\right)}
$$

Hence, by inserting Eq. G into Eq. C, and manipulating it, one obtains the modified Reynolds equation as a function of the porous bearing parameters, as follows:

$$
\begin{aligned}
& \frac{\partial}{\partial \mathrm{x}}\left(\frac{\mathrm{h}^{3} \mathrm{p}}{\eta} \frac{\partial \mathrm{p}}{\partial \mathrm{x}}\right)+\frac{\partial}{\partial \mathrm{y}}\left(\frac{\mathrm{h}^{3} \mathrm{p}}{\eta} \frac{\partial \mathrm{p}}{\partial \mathrm{y}}\right)= \\
& 6 \mathrm{U} \frac{\partial(\mathrm{ph})}{\partial \mathrm{y}}+12 \frac{\partial(\mathrm{ph})}{\partial \mathrm{t}}-\frac{12 \cdot \mathrm{k}_{1}}{\eta \cdot \mathrm{r}_{\mathrm{i}} \ln \left(\mathrm{r}_{\mathrm{o}} / \mathrm{r}_{\mathrm{i}}\right)} \mathrm{p}\left(\mathrm{P}_{\mathrm{s}}-\mathrm{p}\right)
\end{aligned}
$$

Eq. $\mathrm{H}$ can be written in non dimensional form, resulting in the following expression:

$$
\begin{gathered}
\left(\frac{2 \mathrm{~L}_{\mathrm{t}}}{\mathrm{L}}\right)^{2} \frac{\partial}{\partial \overline{\mathrm{x}}}\left(\overline{\mathrm{h}}^{3} \overline{\mathrm{p}} \frac{\partial \overline{\mathrm{p}}}{\partial \overline{\mathrm{x}}}\right)+\frac{\partial}{\partial \overline{\mathrm{y}}}\left(\overline{\mathrm{h}^{3}} \overline{\mathrm{p}} \frac{\partial \overline{\mathrm{p}}}{\partial \overline{\mathrm{y}}}\right)= \\
\Lambda \frac{\partial(\overline{\mathrm{p}} \mathrm{h})}{\partial \overline{\mathrm{y}}}+\Psi \frac{\partial(\overline{\mathrm{p}} \mathrm{h})}{\partial \tau}+\Gamma \overline{\mathrm{p}}(\overline{\mathrm{p}}-1)
\end{gathered}
$$

where:

$$
\Lambda=\frac{6 \eta \mathrm{UL}_{\mathrm{t}}}{\mathrm{c}^{2} \mathrm{P}_{\mathrm{s}}} \quad \Psi=\frac{12 \eta \omega \mathrm{L}_{\mathrm{t}}^{2}}{\mathrm{c}^{2} \mathrm{P}_{\mathrm{s}}} \quad \Gamma=\frac{12 \mathrm{k}_{1} \mathrm{~L}_{\mathrm{t}}^{2}}{\mathrm{c}^{3} \mathrm{r}_{\mathrm{i}} \ln \left(\mathrm{r}_{\mathrm{o}} / \mathrm{r}_{\mathrm{i}}\right)}
$$

The pressure distribution in the bearing gap can be calculated by integrating the modified Reynolds equation (Eq. H or Eq. I). Both aerodynamic and aerostatic effects are computed by these equations, although the aerodynamic effects be very small compared to the aerostatic ones due to low viscosity of the fluid. In the Eq. I, the no dimensional parameter $\Lambda$ is related to the shaft rotating velocity; the non dimensional parameter $\Psi$ is related to the radial excitation frequency of the shaft; and the non dimensional parameter $\Gamma$ is related to the porous medium characteristics of the bearing casing. By setting these parameters, one can achieve specific pressure distributions in the bearing gap, thus affecting the resultant dynamic characteristics of the bearing.

\section{Numerical results}

The non-dimensional modified Reynolds equation (Eq. I) is integrated by adopting central differences of the Finite Difference Method. By setting a mesh grid in the bearing sliding surface one can numerically solve the modified Reynolds equations, thus obtaining the pressure distribution in the bearing gap (pressure values at nodes of the grid). In this work, it was adopted a mesh grid composed of 41 nodes in axial direction and 50 nodes in tangential direction. However, the non-linear terms in the right and left sides of Eq. I require additional computational efforts (iterative procedures).

The non-linear term is a function of $\bar{p}$, which is the main variable and the solution of Eq. I. The Finite Difference Method cannot deal with such non-linearity, and it is not possible to solve both sides of Eq. I simultaneously for achieving $\overline{\mathrm{p}}$. An iterative procedure is necessary for solving Eq. I. By considering that the pressure distribution in i-th iteration is $\bar{p}_{i}$, the pressure distribution in $(i+1)^{- \text {th }}$ iteration is given by:

$$
\begin{aligned}
& \left(\frac{2 \mathrm{~L}_{\mathrm{t}}}{\mathrm{L}}\right)^{2} \frac{\partial}{\partial \overline{\mathrm{x}}}\left(\overline{\mathrm{h}}^{3} \overline{\mathrm{p}}_{\mathrm{i}} \frac{\partial \overline{\mathrm{p}}_{\mathrm{i}+1}}{\partial \overline{\mathrm{x}}}\right)+\frac{\partial}{\partial \overline{\mathrm{y}}}\left(\overline{\mathrm{h}}^{3} \overline{\mathrm{p}}_{\mathrm{i}} \frac{\partial \overline{\mathrm{p}}_{\mathrm{i}+1}}{\partial \overline{\mathrm{y}}}\right)= \\
& \Lambda \frac{\partial(\overline{\mathrm{p}} \overline{\mathrm{h}})}{\partial \overline{\mathrm{y}}}+\Psi \frac{\partial(\overline{\mathrm{p}} \overline{\mathrm{i}})}{\partial \tau}+\Gamma \overline{\mathrm{p}}_{\mathrm{i}}\left(\overline{\mathrm{p}}_{\mathrm{i}}-1\right)
\end{aligned}
$$

The term $\Psi \partial(\overline{\mathrm{p}} \overline{\mathrm{h}}) \partial \tau$ was neglected because only static analyses will be focused on this work.

The iteration procedure can be stopped when the norm $\left|\overline{\mathrm{p}}_{\mathrm{i}+1}-\overline{\mathrm{p}}_{\mathrm{i}}\right|$ lies within an adopted tolerance (in this case $\left.\left|\overline{\mathrm{p}}_{\mathrm{i}+1}-\overline{\mathrm{p}}_{\mathrm{i}}\right| \leq 10^{-2}\right)$. The convergence of the solution is slow; therefore the authors recommend the adoption of efficient numerical procedures in defining $\overline{\mathrm{p}}_{\mathrm{i}}$ before solving Eq. I in a given iteration. In this work, solution convergence was achieved with a reasonable number of iterations (less than 50 iterations) by adopting the Newton-Raphson Method. Ambient pressure is considered as boundary condition at the bearing edges for solving Eq. I.

The aerostatic/aerodynamic forces acting on the shaft can be calculated by integrating the pressure distribution in the inner surface area of the bearing casing (Fig. 9):

$$
\begin{aligned}
& \overline{\mathrm{F}}_{\mathrm{Y}}=\int_{-1}^{1} \int_{0}^{1} \overline{\mathrm{p}} \cos \beta \cdot \mathrm{d} \overline{\mathrm{x}} \cdot \mathrm{d} \overline{\mathrm{y}} \\
& \overline{\mathrm{F}}_{\mathrm{Z}}=\int_{-1}^{1} \int_{0}^{1} \overline{\mathrm{p}} \sin \beta \cdot \mathrm{d} \overline{\mathrm{x}} . \mathrm{d} \overline{\mathrm{y}}
\end{aligned}
$$

The bearing load capacity is given by the resultant aerostatic force obtained for a given rotor eccentricity. The bearing equivalent stiffness coefficients are calculated by a simplification of the proposed perturbation method [18]. The adopted operational conditions in study are listed in Table III. 


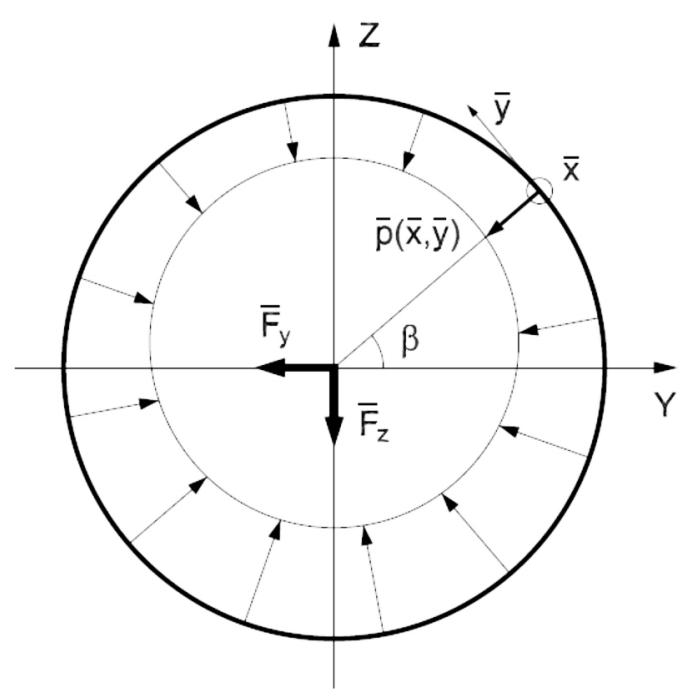

Figure 9: Aerostatic/aerodynamic forces acting on the shaft.

[Figura 9: Forças aerostáticas e aerodinâmicas atuantes no eixo.]

Table III - Operational conditions of the porous bearing in the numerical investigation.

[Tabela III - Condições operacionais do mancal poroso na investigação numérica.]

\begin{tabular}{cc}
\hline Parameter & Range \\
\hline Rotor eccentricity & $\bar{\varepsilon}=0.2,0.5,0.8$ \\
Bearing ratio & $\mathrm{L} / \mathrm{D}=0.25,0.5,1.0$ \\
Rotating velocity parameter & $\Lambda=0.32$ \\
Porous medium parameter & $10<\Gamma<10000$ \\
\hline
\end{tabular}

\section{Bearing load capacity}

Fig. 10 presents the non dimensional bearing load capacity as a function of the non-dimensional parameter $\Gamma$, for a rotor eccentricity $\bar{\varepsilon}=0.5$ and bearing ratio $\mathrm{L} / \mathrm{D}=1.0$. As one can see, the bearing load capacity is a function of the non dimensional parameter $\Gamma$, and presents a maximum value for $\Gamma \cong 60$. On the other hand, parameter $\Gamma$ is a function of bearing geometry and porous permeability coefficient (Eq. I). Hence, depending on the bearing design and on the adopted porous material, one will have a different value of $\Gamma$ for the bearing, and consequently, a different resultant value of bearing load capacity.

Fig. 5 presents the experimental curves of different pore-forming agent (sucrose) concentrations. In Fig. 5, the results with better definition are those for $40 \%$ (uniaxial pressing) and 55\% sucrose concentrations because they present better sample data definition resulting to a more uniform curve. Hence, adopting the permeability coefficients of these materials (Table II), and considering a bearing with the characteristics shown in Table IV, one results in $\Gamma$ values of 450 and 2690 for the $40 \%$ and $55 \%$ sucrose concentrations respectively. Under these conditions, the expected load capacity of the bearings with porous material with $40 \%$ and $55 \%$ sucrose concentrations are shown in Fig. 10 (dot and square symbols).

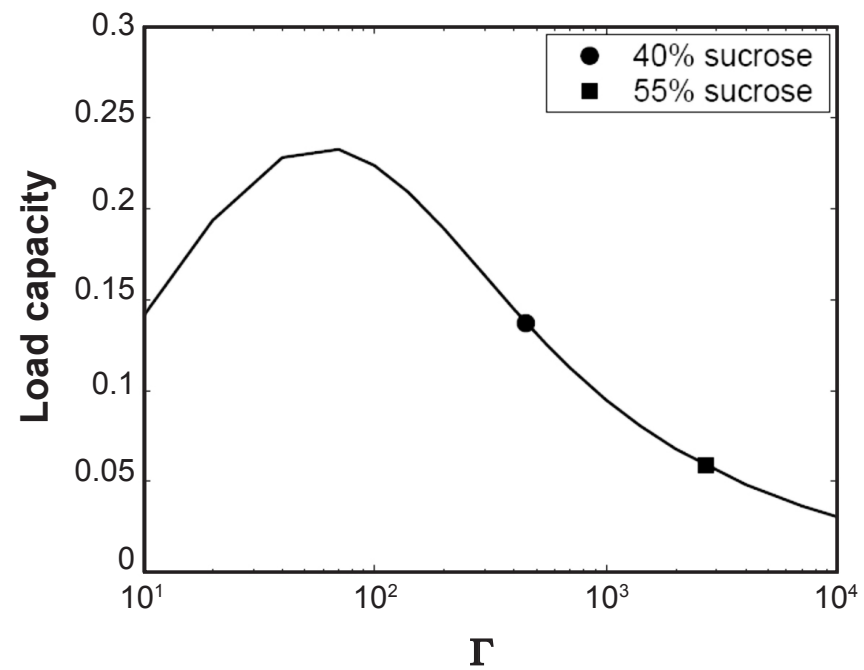

Figure 10: Non dimensional bearing load capacity as a function of $\Gamma(\bar{\varepsilon}=0.5, \mathrm{~L} / \mathrm{D}=1.0)-$ Comparison between materials with different sucrose concentrations.

[Figura 10: Capacidade de carga adimensional do mancal, como função de $\Gamma(\bar{\varepsilon}=0,5, L / D=1,0)$ - Comparação entre materiais com diferentes concentrações de sacarose.]

As one can see in Fig. 10, the porous material with $40 \%$ sucrose concentration results in a bearing with higher load capacity than that with porous material with $55 \%$ sucrose concentration. In this case, the higher permeability coefficient of the material with $55 \%$ sucrose concentration resulted in higher values of parameter $\Gamma$, thus leading to lower values of bearing load capacity.

Fig. 11 presents the bearing load capacity as a function of the non-dimensional parameters $\Gamma$, the rotor eccentricity, and the bearing ratio. As one can see in Fig. 11(a), the behavior is similar to that shown in Fig. 10, where there is a value of $\Gamma$ that result in a maximum bearing load capacity. However, as rotor eccentricity increases, the $\Gamma$ value for maximum load capacity slightly reduces. Moreover, as rotor eccentricity increases, bearing load capacity also increases. Comparing the bearings with different materials, one can see in Fig. 11a that the material with $40 \%$ sucrose concentration still presents better results than those with the material with 55\% sucrose concentration (higher load capacity).

In Fig. $11 \mathrm{~b}$, as the bearing ratio decreases, the $\Gamma$ value for maximum load capacity significantly increases, with a slightly increase in maximum bearing load capacity. Observing the bearings with different materials, one can see that it is possible to build a bearing with $40 \%$ sucrose material resulting in maximum bearing load capacity (optimal design). For that, the bearing ratio must lie between 0.25 and 0.5 (Fig. 11b). The bearing with 55\% sucrose material still presents lower bearing load capacity, and it will only present optimal design (maximum load capacity) for bearing ratio values below 0.25 . Hence, in terms of bearing design, it is possible to initially choose the appropriated bearing ratio (L/D), for a given bearing configuration (geometry and permeability), resulting in 
Table IV - Characteristics of the porous bearing. [Tabela IV - Características do mancal poroso.]

\begin{tabular}{ccc}
\hline Parameter & Value & Dimension \\
\hline Bearing inner radius $\left(\mathrm{r}_{\mathrm{i}}\right)$ & 25 & $\mathrm{~mm}$ \\
Bearing outer radius $\left(\mathrm{r}_{\mathrm{o}}\right)$ & 40 & $\mathrm{~mm}$ \\
Bearing gap $(\mathrm{h})$ & 40 & $\mu \mathrm{m}$ \\
Rotating frequency $(\Omega)$ & 120 & $\mathrm{~Hz}$ \\
Supply pressure $\left(\mathrm{P}_{\mathrm{s}}\right)$ & $0.3 \times 10^{6}$ & $\mathrm{~Pa}$ \\
Air dynamic viscosity $(\eta)$ & $0.18 \times 10^{-6}$ & $\mathrm{~N} . \mathrm{s} / \mathrm{m}^{2}$ \\
\hline
\end{tabular}
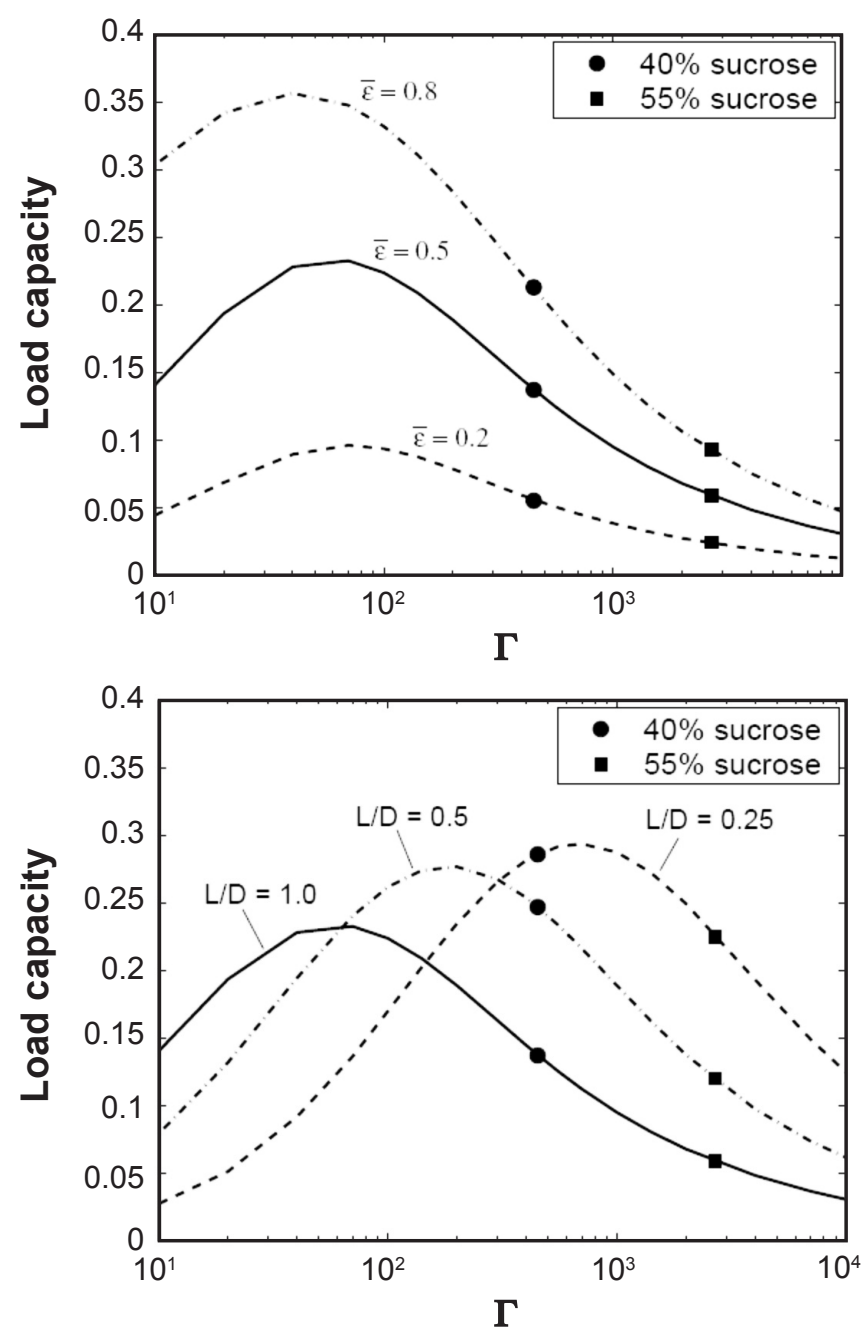

Figure 11: Non dimensional bearing load capacity as a function of $\Gamma$, rotor eccentricity, and bearing ration - Comparison between materials with different sucrose concentrations. a) Eccentricities for $\mathrm{L} / \mathrm{D}=1.0$; b) bearing ratios for $\bar{\varepsilon}=0.5$.

[Figura 11: Capacidade de carga adimensional do mancal, como função de $\Gamma$, excentricidade do rotor e razão do mancal Comparação entre materiais com diferentes concentrações de sacarose. a) excentricidade para $L / D=1,0, b)$ razão do mancal, para $\bar{\varepsilon}=0,5$.]

maximum load capacity. By doing this, one can guarantee maximum load capacity for different rotor eccentricities, because the variation of $\Gamma$ for maximum value is small for changes in rotor eccentricity (Fig. 11a).

\section{Bearing equivalent stiffness}

The stiffness coefficients were calculated based on an auxiliary reference frame aligned with the direction of rotor eccentricity which, in this case, is direction $\xi$ ( $\eta$ is the direction normal to rotor eccentricity). One can consider that the direction of eccentricity is approximately the direction of loading, due to the low cross-coupling effects in aerostatic bearings [19].

Fig. 12 presents the bearing equivalent stiffness coefficients as a function of the non-dimensional parameter $\Gamma$ under rotor eccentricities of $0.2,0.5$ and $0.8(\mathrm{~L} / \mathrm{D}=1.0)$. In this case, rotor eccentricity strongly affects the value of $\Gamma$ for maximum stiffness in the loading direction (eccentricity direction, Fig. 12a). The value of maximum stiffness $\overline{\mathbf{K}}_{\xi \xi}$ itself is also affected by the rotor eccentricity, especially in the case of $\bar{\varepsilon}=0.8$. The maximum stiffness in the direction normal to the eccentricity $\left(\overline{\mathrm{K}}_{n \eta}\right)$ is less affected by the rotor eccentricity (Fig. 12b). The value of $\Gamma$ for maximum stiffness, in the direction normal to the eccentricity, reduces around $50 \%$ from the eccentricity of 0.2 to the eccentricity of $0.8(\mathrm{~L} / \mathrm{D}=1.0)$. However, contrary to the behavior of $\overline{\mathrm{K}}_{\mathrm{E},}$, the value of maximum stiffness $\overline{\mathrm{K}}_{n \eta}$ remains almost constant as rotor eccentricity increases.

Considering the bearings with different materials, one can see in Fig. 12 that the bearing with $40 \%$ sucrose concentration presents higher stiffness than the material with $55 \%$ sucrose concentration. However, in both cases, there is no significant variation of the stiffness due to a variation in rotor eccentricity (Figs. 12a and b). This is caused due to the fact that the bearing equivalent stiffness in both orthogonal directions does not significantly vary as a function of the eccentricity, for $\Gamma$ values above 300 .

It is interesting to note in Fig. 12 that the values of $\Gamma$ for maximum stiffness are not the same for $\overline{\mathrm{K}}_{\xi \xi}$ and $\overline{\mathrm{K}}_{\eta \eta}$, unless rotor eccentricity is small $(\bar{\varepsilon}=0.2)$. This means that, for larger eccentricities than 0.2 , it is not possible to have the maximum stiffness in both directions, by defining a single value of $\Gamma$. In this case, considering bearing design, the definition of parameter $\Gamma$ must take into account what is important to the design (if maximum stiffness in the eccentricity direction, maximum stiffness in the direction normal to eccentricity, or a compromise solution).

Fig. 13 presents the bearing equivalent stiffness coefficients as a function of the non-dimensional parameter $\Gamma$ for bearing ratios of $0.25,0.5$ and $1.0(\bar{\varepsilon}=0.5)$. In this case, the bearing ratio L/D strongly affects the value of $\Gamma$ for maximum stiffness in both orthogonal directions $\left(\overline{\mathbf{K}}_{\xi \xi}\right.$ and $\overline{\mathrm{K}}_{\eta \eta}$, Figs. 13a and b. The value of maximum stiffness in both directions is also strongly affected by the bearing ratio L/D. As shown in Figs. 13a and $b$, the point of maximum stiffness tends to lower values of $\Gamma$ as the bearing ratio increases. Again, it is not possible to have maximum stiffness in both directions by defining a single value of $\Gamma$, because rotor eccentricity is larger than 0.2 .

Considering the different materials, the bearing with $40 \%$ sucrose material presents higher stiffness than that with $55 \%$ 

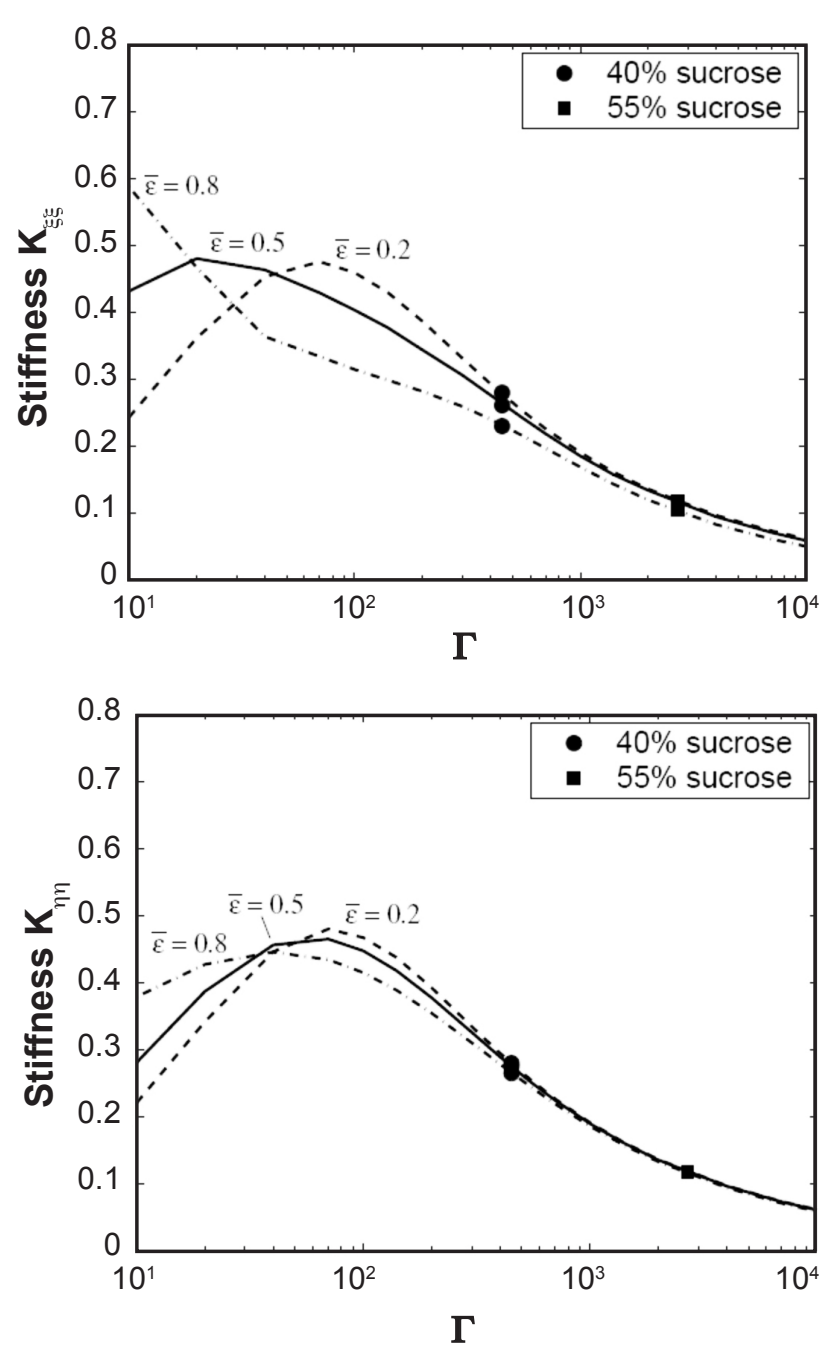

Figure 12: No dimensional bearing equivalent stiffness as a function of $\Gamma$ and rotor eccentricity $(\mathrm{L} / \mathrm{D}=1.0)$ - Comparison between materials with different sucrose concentrations. a) Direction of eccentricity; b) direction normal to eccentricity.

[Figura 12: Rigidez equivalente adimensional do mancal, como função de $\Gamma$ e excentricidade do rotor $(L / D=1,0)$ - Comparação entre materiais com diferentes concentrações de sacarose. a) direção da excentricidade; $b$ ) direção normal da excentricidade.]

sucrose material. In addition, it is possible to build a bearing with $40 \%$ sucrose material resulting in a quasi-maximum equivalent stiffness in both directions by adopting a bearing ratio of 0.25 (compromise solution). If bearing stiffness in loading direction $\left(\overline{\mathrm{K}}_{\xi \xi}\right)$ is more important than the stiffness in normal direction $\left(\overline{\mathbf{K}}_{\eta \eta}^{5 \xi}\right)$, than one shall adopt a bearing ratio value below 0.25 . The bearing with $55 \%$ sucrose material still presents lower equivalent stiffness, and it will only present optimal design (maximum stiffness) for bearing ratio values below 0.25 . Hence, in terms of bearing design, it is possible to initially choose the appropriated bearing ratio $(\mathrm{L} / \mathrm{D})$, for a given bearing configuration (geometry and permeability), resulting in maximum equivalent stiffness coefficient. By doing this, one can guarantee maximum stiffness for different rotor eccentricities because, given a value of $\Gamma$, the variation of the stiffness value is small for
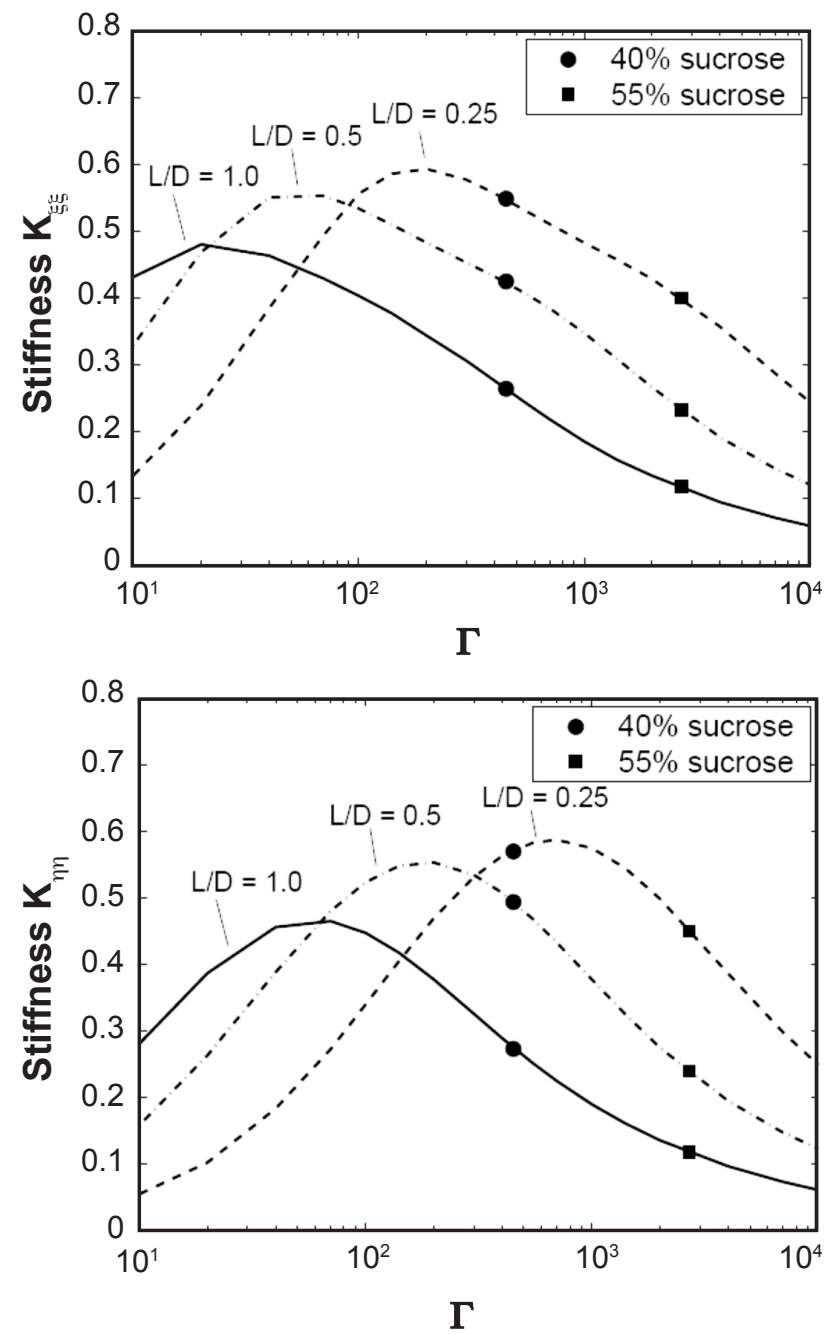

Figure 13: Non dimensional bearing equivalent stiffness as a function of $\Gamma$ and bearing ratio $(\bar{\varepsilon}=0.5)$ - Comparison between materials with different sucrose concentrations. a) direction of eccentricity; b) direction normal to eccentricity.

[Figura 13: Rigidez equivalente adimensional do mancal, como função de $\Gamma$ e razão do mancal $(\bar{\varepsilon}=0,5)$ - Comparação entre materiais com diferentes concentrações de sacarose. a) direção da excentricidade; b) direção normal da excentricidade.]

changes in rotor eccentricity (Fig. 12).

The cross-coupling stiffness coefficients $\overline{\mathrm{K}}_{\xi \eta}$ and $\overline{\mathrm{K}}_{\eta \xi}$, in all cases, remained with values below 0.05 (non-dimensional stiffness) for a broad combination of $\Gamma$ values. However, in bearing design, low direct stiffness regions in Figs. 12 and 13 should be avoided due to rotor stability issues.

\section{CONCLUSIONS}

The identification of ceramic materials for building aerostatic bearings with porous casing is presented. The Reynolds equation is modified by including the Darcy equation that represents the linear pressure-flow relationship in the porous medium. As a consequence, one derives an equation that takes into account both aerodynamic and aerostatic mechanisms in the bearing air film, as a function 
of the porous material permeability. The adoption of sucrose as a pore forming agent resulted in materials with different permeability properties. In this case, the materials with $40 \%$ (uniaxial pressing) and 55\% sucrose concentrations presented a linear behavior of pressure-flow relationship, with low scattering in experimental data. Hence, the assumption of linearity in the pressure-flow relationship in porous medium is reasonable and the modified Reynolds equation can be applied. Numerical results on the bearing load capacity and equivalent stiffness show that the material with $40 \%$ sucrose concentration is a better choice for building the aerostatic bearing with properties of Table IV, when compared to the $55 \%$ sucrose concentration material. This is caused due to the lower permeability coefficient of the $40 \%$ sucrose material, which leads to a lower value of the non dimensional parameter $\Gamma$, neighboring the optimum values. The optimality can be achieved by setting appropriated values of bearing ratio $\mathrm{L} / \mathrm{D}$. Hence, in the design process of an aerostatic ceramic porous bearing, the engineer may have in hands a set of materials with different forming pore agents, together with their respective permeability coefficients, in order to obtain an optimum load capacity and equivalent stiffness in the bearing. By choosing the appropriated material for the desired geometry of the bearing and suitable $\mathrm{L} / \mathrm{D}$ bearing ratios, the engineer will be able to obtain $\Gamma$ for optimum load capacity and stiffness.

\section{ACKNOWLEDGEMENTS}

The Brazilian research foundations FAPESP and CNPq are gratefully acknowledged for the support given to this project. Prof. O. Assis, from the Brazilian research institute EMBRAPA - Center of Agricultural Instrumentation, is also acknowledged for the support in the experimental set-up preparation.

\section{REFERENCES}

[1] L. A. P. Balestrero, An evaluation of aerostatic bearings for machine tools: study and dimensioning of a spindle shaft, D.Sc Thesis, Escola de Engenharia de S. Carlos, S. Carlos, SP, Brazil (1997) in Portuguese.

[2] B. C. Majumdar, Tribology Int. 19 (1976) 71.

[3] S. Yoshimoto, K. Kohno, K, J. Tribology 123, 3 (2001) 501.

[4] M. Fourka, M. Bonis, Wear 210 (1997) 311.

[5] J. S. Plante, J. Vogan, T. El-Aguizy, A. H. Slocum, Precision Eng. 29, 3 (2005) 336.

[6] B. C. Majumdar, Wear 24, 1 (1973) 15.

[7] B. C. Majumdar, J. Mech. Eng. Sci. 22, 2 (1980) 55.

[8] Y. B. P. Kwan, J. Corbett, Tribology Int. 31, 12 (1998) 779.

[9] Y. B. P. Kwan, J. Corbett, Wear 222 (1998) 69.

[10] C. A. Fortulan, S. R. Fontes, R. A. Ikegami, B. M. Purquerio, $49^{\circ}$ Cong. Bras. Ceram., S. Pedro, SP, Brazil (2005).

[11] F. H. Monaretti, C. C. Camilo, R. A. Ikegami, C. A. Fortulan, B. M. Purquerio, $49^{\circ}$ Cong. Bras. Ceram., S. Pedro, SP, Brazil (2005).

[12] R. A. Vasques, Rev. Fís. Apl. Instr. 14, 4 (1999) 120.

[13] G. Belforte, T. Raparelli, V. Viktorov, A. Trivella, $8^{\text {th }}$ Biennial ASME Conf. Eng. Systems Design and Analysis, Torino, Italy (2006) 1.

[14] R. Nicoletti, Z. C. Silveira, B. M. Purquerio, ASME/ STLE 2007 Int. Joint Tribology Conf., San Diego, USA (2007) 1.

[15] ISO 4022, Permeable sintered metal materials - Determination of fluid permeability, International Organization for Standardization (1987).

[16] G. T. F. Kilmister, Powder Metallurgy 12, 24 (1969) 400.

[17] K. Cieslicki, Wear 172 (1994) 73.

[18] P. E. Allaire, J. A. Parsell, L. E. Barrett, Wear 72 (1981) 29.

[19] B. J. Hamrock, S. R. Schmid, B. O. Jacobson, Fundamentals of fluid film lubrication, Marcel Dekker Inc., New York, USA (1994).

(Rec. 13/04/2009, Ac. 07/08/2009) 